\title{
Effects of the asymmetric riser and bilge keel arrangements on FPSO green water assessment
}

Shuo Wang, Xin Wang*, Wai Lok Woo

Newcastle University, NE1 7RU, United Kingdom

*Corresponding author: xin.wang@ncl.ac.uk

\begin{abstract}
This article aims to report important findings on how the asymmetric riser and bilge keel arrangements affect the motion response and green water assessment by using a real FPSO conversion project. Recently, the authors have proposed a practical approach for short-term and long-term green water prediction. In this paper, the method has been further extended to include the effect of truncated bilge keel by using Morrison elements. Numerical studies are conducted focusing on the effect induced by asymmetric riser arrangement and truncated bilge keels. Comparisons of short-term and long-term results between different models indicate that the FPSO's motion is significantly affected by asymmetrically arranged appendages and attachments in a complicated way. The relative wave elevation is also affected by appendages and attachments, but not the same trend as the motion response. The effect of the asymmetric arrangement of risers and bilge keel on long-term relative wave elevation response has been captured by both traditional contour line approach and response-based analysis, but some discrepancy identified between the results from the two methods indicates the limitation of the traditional contour line approach.
\end{abstract}

Keywords: Green water; Relative wave elevation; Asymmetric risers; Truncated bilge keel; Response-based analysis; Short-term and Long-term prediction 


\section{Introduction}

Floating, production, storage and offloading units (FPSOs) often encounter green water incidents during severe environmental conditions. In severe sea-states, when the freeboard of ship is exceeded by the violent wave, a significant amount of water can flow onto the deck, possibly damaging topside structures and equipment. Different from conventional cargo ships, an FPSO has more appendages and attachments with various designs, i.e., the mooring system and riser. It has been found in some studies that the green water assessment can be significantly affected by the appendages and attachments [1,2]. Buchner [1] studied the green water on an FPSO model using linear potential theory, and the recommendation was given to include the stiffness and weight from the mooring system in simulations for real projects. In Greco et al. [2], the effect of bilge keel damping on the parametric roll and water-on-deck event of an FPSO was also predicted numerically. In industry practice, it is desirable to include the appendages and attachments when assessing the risk of green water in the early design stage. However, full effects of appendages and attachments on green water assessment, especially the asymmetric riser arrangement have rarely been studied, leaving a possible gap between academic researches and industrial applications.

For FPSOs with spread mooring, risers are usually allocated along one side of the hull. This asymmetric arrangement is selected for some practical considerations. The risers for spread mooring FPSOs are commonly located along the length of the FPSO hull, so that large amount of risers can be accommodated, with additional flexibility for riser installation and expansion [3]. Arranging the risers at one side of the FPSO will allow the other side to be available for cargo handling and the approaching of supply vessels [4]. For the vessels with asymmetric riser arrangement, a truncated bilge keel design is usually used: the bilge keel at one side is truncated to avoid risers and offloading hawsers being damaged by the sharp edge of the bilge keel. Example of such type of bilge keel design can be found in Veer et al. [5]. To compensate for the loss of roll damping due to the truncation, the size of the bilge keel at the opposite side may be increased accordingly [6].

Some recent studies have indicated that the asymmetric risers and truncated bilge keel might significantly affect the roll response of an FPSO and there have been some attempts to capture this phenomenon numerically. Ferreira et al. [4] suggested a simplified frequency domain approach to qualitatively represent the effect of asymmetric risers, by representing the riser effect with asymmetric linear damping terms; Tom et al. [6] simulated the FPSO in the time domain using Orcaflex, with truncated bilge keel design represented by Morrison element of unequal length. The asymmetric roll response as suggested by experiments was captured in their numerical analysis. Seah et al. [7] performed the simulation in time domain, using the improved formulation of Morrison drag coefficient characterized by the Keulegan-Carpenter number (KC). The KC-dependent drag coefficient was also implemented by Bigot et al. [8] in the frequency domain simulation, and results comparison indicated that the constant drag coefficient is already performing very well. Rezende et al. [9] illustrated significant heave-roll coupling effect on FPSO caused by the damping effect from asymmetric risers, by using a simplified frequency-domain approach following the method of Bigot et.al [8]. By conducting the numerical analysis of the forced oscillation, they concluded that the inertial effect of the riser is negligible.

The studies above only focused on the FPSO motion response but did not consider its effects on green water assessment. Besides, the understanding on the combined effect of the one-side riser arrangement with truncated bilge keel design seems to be insufficient, and a frequency domain approach for practical application appears to be uncompleted.

In our recent work, we have proposed a practical numerical approach for short-term and long-term green water prediction [10-13]. By applying stochastic linearization to the quadratic damping and including off-diagonal terms for asymmetric riser arrangement, the nonlinear effects due to bilge keel, mooring and riser are included in frequency domain analysis, without sacrificing on the computational efficiency. The adequacy of the proposed frequency domain approach has been validated by comparing the motion response result with fully coupled time domain analysis, and the predicted relative wave elevation with lab test measurement.

In this article, the above method has been further extended to consider the effect of truncated bilge keel. The drag force on the bilge keel at each side is simulated using Morrison-type drag force. This approach is integrated 
into the frequency domain analysis, by applying stochastic linearization to the quadratic drag force at each side of the hull. With this extended numerical method, we have focused on the effects of the one-side riser arrangement combined with truncated bilge keel design. Their impact on the short-term and long-term green water assessment are presented and explained in this paper.

\section{Methodology}

\subsection{Short-term prediction of the relative wave elevation}

A summary of the numerical method is provided below, in which the effects of bilge keel, mooring, and port side risers are considered as additional stiffness, added mass and damping parameters. Validations of this approach on an FPSO with symmetrical bilge keel and port-side risers can be found in Wang et al. [10] [11]. For a spread mooring FPSO with bilge keel and risers, the vessel's motion equation can be expressed as below.

$$
\left[\mathbf{H}_{\text {hull }}+\mathbf{H}_{\mathbf{m}}+\mathbf{H}_{\mathrm{bk}}+\mathbf{H}_{\text {riser }}\right] \cdot \mathbf{X}=\mathbf{F}_{\mathbf{W}}
$$

where $\mathbf{H}_{\text {hull }}, \mathbf{H}_{\mathbf{m}}, \mathbf{H}_{\mathbf{b k}}$, and $\mathbf{H}_{\text {riser }}$ are the transfer matrix of the FPSO hull, mooring systems, bilge keel, and risers, respectively. $\mathbf{X}$ is the hull motion vector and $\mathbf{F}_{\mathbf{W}}$ is the wave force vector.

$\mathbf{H}_{\text {hull }}$ is the transfer matrix due to the FPSO hull, which is calculated as

$$
\mathbf{H}_{\text {hull }}=-\omega^{2}\left(\mathbf{M}_{\text {hull }}+\mathbf{A}_{\text {hull }}\right)+i \omega \mathbf{B}_{\text {hull }}+\mathbf{K}_{\text {hull }}
$$

which consists of the inertia matrix $\mathbf{M}_{\text {hull }}$, radiation added mass matrix $\mathbf{A}_{\text {hull }}$, radiation damping matrix $\mathbf{B}_{\text {hull }}$, and hydrostatic stiffness matrix $\mathbf{K}_{\text {hull }}$. $\omega$ is the motion frequency in $\mathrm{rad} / \mathrm{s}$.

$\mathbf{H}_{\mathbf{m}}$ is the transfer matrix due to the mooring system, calculated as

$$
\mathbf{H}_{\mathbf{m}}=-\omega^{2}\left(\mathbf{M}_{\mathbf{m}}+\mathbf{A}_{\mathbf{m}}\right)+i \omega\left(\mathbf{B}_{\mathbf{m}}+\tilde{\mathbf{B}}_{\mathbf{m}}^{\mathbf{q}}\right)+\mathbf{K}_{\mathbf{m}}
$$

Where $\mathbf{M}_{\mathbf{m}}, \mathbf{A}_{\mathbf{m}}, \mathbf{B}_{\mathbf{m}}$, and $\mathbf{K}_{\mathbf{m}}$ are the mass, added mass, linear damping and stiffness matrix. $\tilde{\mathbf{B}}_{\mathbf{m}}^{\mathbf{q}}$ is the linearized quadratic damping matrix, which gives same energy dissipation as the original quadratic damping $\mathbf{B}_{\mathbf{m}}^{\mathbf{q}}$ in the specified sea-state. The motion in all 6 DOFs are considered as affected by the spread mooring system. Stiffness matrix of $6 \mathrm{x} 6$ is derived from the catenary equations. Added mass, linear and quadratic damping coefficients in surge, sway, heave and roll are further obtained by numerical free decay analysis. In the present method, stochastic linearization is adopted to obtain the linearized quadratic damping $\tilde{\mathbf{B}}_{\mathbf{m}}^{\mathbf{q}}$. Stochastic linearization is valid for systems as a Gaussian process and is often used for ship motion analysis in irregular waves $[12,13]$. The details of the linearization approach are explained in the Appendix.

$\mathbf{H}_{\text {riser }}$ is the hydrodynamic transfer matrix due to the risers at one side. Due to the nature of risers to be flexible lines, the riser load acting on the FPSO hull would generally be along the line direction. Considering the direction of risers near to riser connectors to be close to vertical, the magnitude of terms in surge and sway are small, and thus can be neglected. Usually, the centre of gravity (COG) of an FPSO and the riser balcony are located close to the midship. Assuming that both the COG and the risers are located at the midship, the pitch and yaw moments induced by the risers can also be neglected. Thus, only the heave force and roll moment induced by the risers are considered in this study, which can be expressed as

$$
\begin{aligned}
& F_{3}=\left\{-\omega^{2}\left(M_{\text {riser }}+A_{\text {riser }}\right)+i \omega\left(B_{\text {riser }}+B_{\text {riser }}^{q}\left|V_{\text {riser }}\right|\right)+K_{\text {riser }}\right\}\left\{X_{3} \pm X_{4}\left(\frac{B}{2}\right)\right\} \\
& M_{4}=F_{3}\left( \pm \frac{B}{2}\right)
\end{aligned}
$$

where $B$ denotes the beam of the hull, $(+)$ is applied for portside risers and $(-)$ for starboard risers. $V_{\text {riser }}$ is the local vertical velocity at the riser connection, and is given by 


$$
V_{\text {riser }}=i \omega\left\{X_{3} \pm X_{4}\left(\frac{B}{2}\right)\right\}
$$

By applying stochastic linearization, the quadratic damping term $B_{\text {riser }}^{q}\left|V_{\text {riser }}\right|$ can be transformed to an equivalent linear damping term $\tilde{B}_{r i s e r}^{q}$. Thus, Eq. (4) becomes

$$
\begin{aligned}
& F_{3}=\left\{-\omega^{2}\left(M_{\text {riser }}+A_{\text {riser }}\right)+i \omega\left(B_{\text {riser }}+\tilde{B}_{\text {riser }}^{q}\right)+K_{\text {riser }}\right\}\left\{X_{3} \pm X_{4}\left(\frac{B}{2}\right)\right\} \\
& M_{4}=F_{3}\left( \pm \frac{B}{2}\right)
\end{aligned}
$$

Based on the above derivation, the definition of $\mathbf{H}_{\text {riser }}$ can now be given as below.

$$
\mathbf{H}_{\text {riser }}=\left[\begin{array}{cccccc}
0 & 0 & 0 & 0 & 0 & 0 \\
0 & 0 & 0 & 0 & 0 & 0 \\
0 & 0 & H_{\text {riser }}^{33} & H_{\text {riser }}^{34} & 0 & 0 \\
0 & 0 & H_{\text {riser }}^{43} & H_{\text {riser }}^{44} & 0 & 0 \\
0 & 0 & 0 & 0 & 0 & 0 \\
0 & 0 & 0 & 0 & 0 & 0
\end{array}\right]
$$

Here, $H_{\text {riser }}^{33}$ is the complex transfer function of heave due to risers, consists of mass and added mass of riser $M_{\text {riser }}+A_{\text {riser }}$, linear damping $B_{\text {riser }}$, linearized quadratic damping $\tilde{B}_{\text {riser }}^{q}$, and stiffness $K_{\text {riser }}$.

$$
H_{\text {riser }}^{33}=-\omega^{2}\left(M_{\text {riser }}+A_{\text {riser }}\right)+i \omega\left(B_{\text {riser }}+\tilde{B}_{\text {riser }}^{q}\right)+K_{\text {riser }}
$$

$H_{\text {riser }}^{34}, H_{\text {riser }}^{43}$, and $H_{\text {riser }}^{44}$ are the transfer functions accounting for the heave-roll coupling effect induced by the riser lines, defined as below.

$$
\begin{gathered}
H_{\text {riser }}^{34}=H_{\text {riser }}^{43}=H_{\text {riser }}^{33} \cdot\left( \pm \frac{B}{2}\right) \\
H_{\text {riser }}^{44}=H_{\text {riser }}^{33} \cdot\left(\frac{B}{2}\right)^{2}
\end{gathered}
$$

As explained above, $(+)$ is applied for portside risers and $(-)$ for starboard risers.

$\mathbf{H}_{\mathbf{b k}}$ is the transfer matrix due to the bilge keels. Same as the riser matrix, the bilge keel on each side is separately considered.

$$
\mathbf{H}_{\mathrm{bk}}=\mathbf{H}_{\mathrm{bk}}^{\mathrm{L}}+\mathbf{H}_{\mathrm{bk}}^{\mathrm{R}}
$$

To derive the components of $\mathbf{H}_{\mathbf{b k}}^{\mathbf{L}(\mathbf{R})}$, Morrison elements have been applied to the bilge keel at each side. In the present work, the method similar to Bigot et al. [8] is applied to simulate bilge keel in frequency domain, with constant drag coefficient. The drag force on a bilge keel, $F_{b k}$, which is normal to the bilge keel, is given by the Morrison drag formula,

$$
F_{b k}=0.5 \cdot \rho \cdot S_{b k} \cdot C_{D} \cdot\left|V_{b k}\right| V_{b k}
$$

where $\rho$ is the sea water density, $S_{b k}$ is the bilge keel area, $C_{D}$ is the non-dimensional Morrison drag coefficient, and $V_{b k}$ is the local velocity normal to the bilge keel. Assuming that the bilge-keel breath is small as compared to the vessel breadth, $V_{b k}$ can be obtained by

$$
V_{b k}=i \omega\left\{ \pm X_{2} \sin \theta+X_{3} \cos \theta \pm X_{4}\left(\frac{B}{2} \cos \theta+d \sin \theta\right)\right\}
$$


As defined in Fig. 1, $d$ is the depth of the bilge keel under the center of gravity, and $\theta$ is the angel of the bilge keel; (+) is applied for portside bilge keel and (-) for starboard bilge keel.

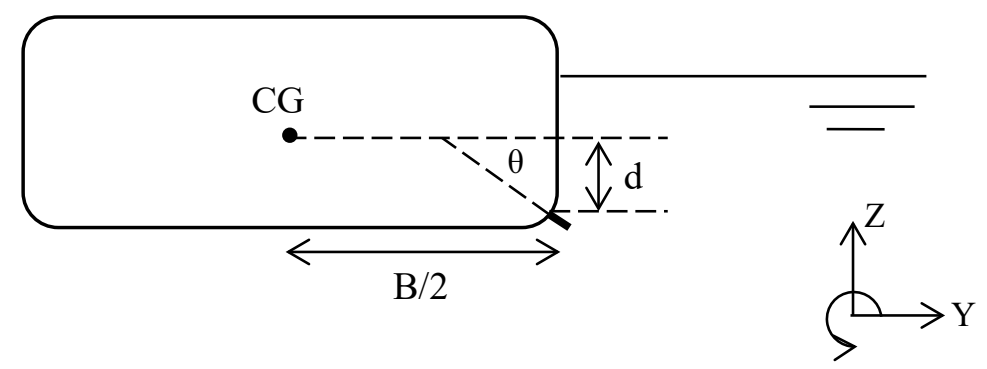

Figure 1. Local velocity definition at the bilge keel

Thus, the quadratic damping coefficient of the bilge keel is given as

$$
B_{b k}^{q}=0.5 \cdot \rho \cdot S_{b k} \cdot C_{D}
$$

Applying the stochastic linearization, the equivalent linear damping coefficient $\tilde{B}_{b k}^{q}$ can be obtained. The forces and moments induced by the bilge keel can then be calculated as

$$
\begin{aligned}
& F_{2}= \pm \tilde{B}_{b k}^{q} V_{b k} \sin \theta \\
& F_{3}=\tilde{B}_{b k}^{q} V_{b k} \cos \theta \\
& M_{4}=F_{2} d \pm F_{3}\left(\frac{B}{2}\right)
\end{aligned}
$$

Substituting Eq. (13) into Eq. (15), the forces and moments can be split into sway, heave and roll components in the bilge keel transfer matrix. Thus, $\mathbf{H}_{\mathbf{b k}}^{\mathbf{L}(\mathbf{R})}$ is defined as

$$
\mathbf{H}_{\mathbf{b k}}^{\mathbf{L}(\mathbf{R})}=\left[\begin{array}{cccccc}
0 & 0 & 0 & 0 & 0 & 0 \\
0 & H_{b k}^{22} & H_{b k}^{23} & H_{b k}^{24} & 0 & 0 \\
0 & H_{b k}^{32} & H_{b k}^{33} & H_{b k}^{34} & 0 & 0 \\
0 & H_{b k}^{42} & H_{b k}^{43} & H_{b k}^{44} & 0 & 0 \\
0 & 0 & 0 & 0 & 0 & 0 \\
0 & 0 & 0 & 0 & 0 & 0
\end{array}\right]
$$

Here,

$$
\begin{aligned}
& H_{b k}^{22}=i \omega \tilde{B}_{b k}^{q} \sin ^{2} \theta \\
& H_{b k}^{23}=H_{b k}^{32}= \pm i \omega \tilde{B}_{b k}^{q} \sin \theta \cos \theta \\
& H_{b k}^{24}=H_{b k}^{42}=i \omega \tilde{B}_{b k}^{q} \sin \theta\left(\frac{B}{2} \cos \theta+d \sin \theta\right) \\
& H_{b k}^{33}=i \omega \tilde{B}_{b k}^{q} \cos ^{2} \theta \\
& H_{b k}^{34}=H_{b k}^{43}= \pm i \omega \tilde{B}_{b k}^{q} \cos \theta\left(\frac{B}{2} \cos \theta+d \sin \theta\right) \\
& H_{b k}^{44}=i \omega \tilde{B}_{b k}^{q}\left(\frac{B}{2} \cos \theta+d \sin \theta\right)^{2}
\end{aligned}
$$

By solving Eq. (1) in frequency domain, the vertical motion $z$ at a target location on the FPSO can be calculated. Together with radiation and diffraction wave elevations $\zeta_{1-7}$ and incident wave elevation $\zeta_{0}$, the relative wave motion (RWE) can be evaluated, 


$$
R W E=\zeta_{0}+\sum_{1}^{6} \zeta_{i}+\zeta_{7}-z
$$

With the solution of relative wave motion obtained in frequency domain, the significant value of relative wave motion, $\mathrm{RWE}_{\mathrm{sig}}$, and zero-crossing period, $T_{z}$, can be evaluated with the method proposed by Ochi [15].

$$
\begin{gathered}
S_{\eta \eta}=S_{\eta} \cdot\left(\frac{R W E}{\zeta_{0}}\right)^{2} \\
R W E_{s i g}=2 \sqrt{\int S_{\eta \eta} d \omega} \\
T_{Z}=2 \pi \sqrt{\frac{\int S_{\eta \eta} d \omega}{\int \omega^{2} S_{\eta \eta} d \omega}}
\end{gathered}
$$

where $S_{\eta}$ is the power spectral density of the irregular incident wave, and $S_{\eta \eta}$ is the power spectral density of the RWE response.

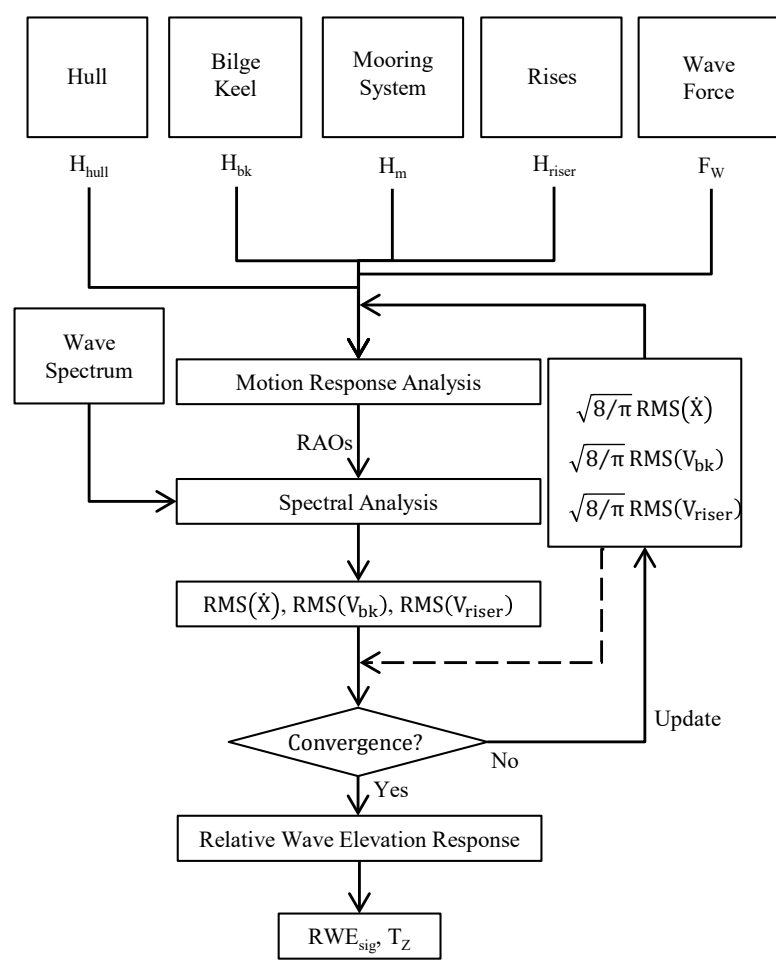

Figure 2. Flowchart of the short-term relative wave elevation prediction

The flowchart for evaluating relative wave elevation is present in Fig. 2. After substituting Eq. (2)-(17) into Eq. (1) , the equation can be solved via an iterative approach. The solving process starts with initial assumptions on the input velocity terms $\operatorname{RMS}(\dot{\mathrm{X}}), \operatorname{RMS}\left(V_{b k}\right)$ and $\operatorname{RMS}\left(V_{\text {riser }}\right)$, so that the quadratic damping can be linearized. Solving the linearized Eq. (1) followed by spectral analysis, a new set of the assumed velocity terms can be obtained as output. By updating the input velocity terms with the output results, and repeat the operation until the discrepancies between input and output velocity terms are negligible, Eq. (1) is solved iteratively, and the solution can be further used to evaluate RWE results. The relative wave elevation may be used directly for green water risk assessment, or as input information for further analysis on green water incident.

\subsection{Long-term extreme response of the relative wave elevation using response-based analysis}

By combining the short-term response analysis and the long-term environmental condition, the response of FPSO in the long term can be estimated. In traditional industrial practice, the extreme response like FPSO 
motion, mooring line tension or green water height, are usually evaluated using environmental contour line approach, which defines the extreme short-term response in the "most un-favored" sea-state (i.e., 100-yr return wave spectrum) as the worst design value. In contrast to the contour line method, the long-term extreme response may also be obtained from the response-based analysis (RBA), in which the extreme response is estimated considering all possible sea-states.

The long-term wave conditions are usually described statistically as joint distribution, taking the significant wave height and zero crossing period or spectrum peak period as two variables. The joint distribution can generally be expressed in two types of statistical models: bi-variate distribution and combination of marginal distribution with conditional distribution. Comparison between different types of joint distribution models can be found in Burrows and Salih [16] and Teng and Palao [17]. In the present study, bi-variate lognormal distribution formulation is selected to express the fictitious long-term sea-state distribution, similar to the formulation proposed by Ochi [18]. The fictitious omni-directional long-term wave distribution model for the study is as shown in Eq. (22)

$$
\begin{aligned}
f\left(H_{s}, T_{p}\right)= & \frac{1}{2 \pi H_{s} T_{p} \sigma_{h} \sigma_{t} \sqrt{1-\rho^{2}}} \\
& \times \exp \left\{-\frac{1}{2\left(1-\rho^{2}\right)}\left[\frac{\left(\ln \left(H_{s}\right)-\lambda_{h}\right)^{2}}{\sigma_{h}^{2}}-\frac{2 \rho\left(\ln \left(H_{s}\right)-\lambda_{h}\right)\left(\ln \left(T_{p}\right)-\lambda_{t}\right)}{\sigma_{h} \sigma_{t}}+\frac{\left(\ln \left(T_{p}\right)-\lambda_{t}\right)^{2}}{\sigma_{t}{ }^{2}}\right]\right\}
\end{aligned}
$$

Where $f\left(H_{s}, T_{p}\right)$ is the probability density for sea-state with a significant wave height of $H_{s}$ and peak period of $T_{p}$, and $\left(\sigma_{h}, \sigma_{t}, \lambda_{h}, \lambda_{t}, \rho\right)$ are parameters for the statistical model.

With significant value and zero crossing period of relative wave elevation $\mathrm{RWE}_{\text {sig }}$ and $T_{z}$ from a specific wave spectrum, the most probable maximum RWE response in the $3 \mathrm{~h}$ sea-state, RWEMPM, can be derived from Rayleigh distribution and expressed as Eq. (23).

$$
R W E_{M P M}=R W E_{s i g} \cdot \sqrt{\frac{1}{2} \ln \left(\frac{3 h r}{T_{Z}}\right)}
$$

To apply traditional contour line approach, the environmental contour line for target period of return needs to be firstly evaluated from the long term sea-state distribution data. The computation of environmental contour line using DNV method starts by evaluating the $\mathrm{H}_{\mathrm{S}}$ of the target return period in its marginal distribution, and the median value of $\mathrm{T}_{\mathrm{P}}$ in its conditional distribution corresponding to the evaluated $\mathrm{H}_{\mathrm{S}}$. The environmental contour line can then be established from the joint distribution model as the contour of constant probability density passing through the $\mathrm{H}_{S}$ and $\mathrm{T}_{\mathrm{P}}$ evaluated above. DNV also provides another method named inversed First Order Reliable Method (iFORM), which performs similar operation but in standard normalized U-space from Rosenblatt transformation. After getting the environmental contour data for target return period, Eq. (23) can be applied on all sea-states from the contour, and the most severe result is considered as the long-term RWE extreme response.

Besides the traditional contour line approach, the long-term response may also be obtained from all relevant sea-states using RBA. The cumulative probability of RWE response below a selected threshold $X, F\left(X \mid H_{s}, T_{p}\right)$ , can be derived as Eq. (24). The corresponding year-of-return for $X, N_{Y R}(X)$, can then be evaluated using Eq. (25). The threshold $X$ is considered as the RBA long-term response result with $N_{Y R}(X)$ year-of-return.

$$
F\left(X \mid H_{s}, T_{p}\right)=1-\exp \left[-2\left(\frac{X}{R W E_{\text {sig }}}\right)^{2}\right]
$$




$$
N_{Y R}(X)=\left(1-\int_{H_{s} T_{p}} F\left(X \mid H_{s}, T_{p}\right) \cdot \frac{3 h r}{T_{Z}} \cdot f\left(H_{s}, T_{p}\right) d H_{s} d T_{p}\right)^{-1}
$$

Contour line method separates the calculation of long term statistics and short-term simulation, thus obtaining the long-term estimation with much lower computational cost than RBA. However, numerical study on longterm response of FPSO green water by Wang et al. [12] shows that the short-term response affected by various types of nonlinearities will cause the combined response pattern to be different from the long-term environmental state distribution, and the actual probability of exceedance for the extreme response from contour line method may not be accurate. Besides, different definitions and methods for long term environmental statistics also affect the response estimation: as an example, 100-yr return sea-states from Highest Density Contour (HDC) method proposed by Haselsteiner et al. [19] appear to be always more severe than from method in DNV-RP-C205 [20]. The long-term response from traditional approach can thus be seen as a practical approximation, which is computationally much cheaper but less reliable than response-based analysis. In this study, both the results using the contour line approach and the response-based analysis are presented and compared.

\section{The numerical model of a spread mooring FPSO and simulation conditions}

The FPSO model used in the case studies are based on a past spread mooring FPSO conversion project, with some modification on the bilge keel design, as well as the arrangement of mooring and risers. Some main particulars of the FPSO hull are presented in Table 1, and the modified FPSO model used in the case studies are summarized in Table 2. Comparisons among model A, B and C are used to investigate the effects of asymmetric risers and truncated bilge keel.

A group of JONSWAP wave spectra used in the example of API-RP-2SK [21] are applied in the short-term prediction, which are listed in Table 3. Motion analyses are carried out with all the 10 wave spectra in Table 3 . RWEs of the FPSO at the side facing the incident wave are evaluated only with selected wave spectra. The RWE are evaluated at five selected locations on the FPSO, as listed in Table 4.

Table 1. Particulars of FPSO hull (full scale)

\begin{tabular}{ll}
\hline Principle Parameters & Value \\
\hline Displacement & 122637 Ton \\
Water Depth & $277.00 \mathrm{~m}$ \\
Draft & $14.62 \mathrm{~m}$ \\
Transverse GM & $5.36 \mathrm{~m}$ \\
\hline
\end{tabular}

Table 2. Summary of FPSO model for case studies

\begin{tabular}{lllll}
\hline Model & Mooring & Risers & Bilge Keel & Wave Direction \\
\hline A & Spread & No & Symmetric & $90^{\circ} ; 135^{\circ}$ \\
B & Spread & Port side & Symmetric & $\pm 90^{\circ} ; \pm 135^{\circ}$ \\
C & Spread & Port side & Truncated (PS: $-25 \%$; SB: $+25 \%)$ & $\pm 90^{\circ}$ \\
\hline
\end{tabular}

Table 3. JONSWAP irregular wave spectrum for case studies

\begin{tabular}{lllllllllll}
\hline No. & $\mathbf{1}$ & $\mathbf{2}$ & $\mathbf{3}$ & $\mathbf{4}$ & $\mathbf{5}$ & $\mathbf{6}$ & $\mathbf{7}$ & $\mathbf{8}$ & $\mathbf{9}$ & $\mathbf{1 0}$ \\
\hline $\mathrm{Hs}$ & 1.10 & 2.53 & 3.97 & 5.40 & 6.83 & 8.27 & 9.70 & 11.13 & 12.57 & 14.00 \\
$\mathrm{Tp}$ & 8.4 & 9.2 & 10.4 & 11.6 & 12.7 & 13.6 & 14.4 & 15.3 & 16.1 & 17.7 \\
$\gamma$ & 3.3 & 3.3 & 3.3 & 3.3 & 3.3 & 3.3 & 3.3 & 3.3 & 3.3 & 3.3 \\
\hline
\end{tabular}


Table 4. Locations for RWE calculation

\begin{tabular}{llllll}
\hline Location No. & $\mathbf{1}$ & $\mathbf{2}$ & $\mathbf{3}$ & $\mathbf{4}$ & $\mathbf{5}$ \\
\hline Location for RWE & Bow & Fore Ship* & Mid Ship* & Aft Mid* & Stern \\
\hline *RWE are evaluated at the side of the FPSO facing the incident wave &
\end{tabular}

For long-term response analysis in the present study, bi-variate lognormal distribution formulation is selected to express the fictitious long-term sea-state distribution, similar to the formulation proposed by Ochi [18]. The parameters used in fictitious omni-directional long-term wave distribution model for the study are shown in Table 5. The assumption of directional probability is presented in Table 6. Each 3-hr irregular sea-states are expressed with JONSWAP spectrum. For the traditional contour line method, the selected 100-yr return seastates for quartering sea and beam sea using the method from DNV [20] are summarized in Table 7.

Table 5. Parameters for Long Term Wave Distribution Model

\begin{tabular}{lll}
\hline Parameter & Definition & Value \\
\hline$\lambda_{h}$ & Expectation of $\ln \left(\mathrm{H}_{\mathrm{S}}\right)$ & 0.50 \\
$\lambda_{t}$ & Expectation of $\ln \left(\mathrm{T}_{\mathrm{P}}\right)$ & 1.70 \\
$\sigma_{\mathrm{h}}$ & Standard Deviation of $\ln \left(\mathrm{H}_{\mathrm{S}}\right)$ & 0.40 \\
$\sigma_{\mathrm{t}}$ & Standard Deviation of $\ln \left(\mathrm{T}_{\mathrm{P}}\right)$ & 0.30 \\
$\rho$ & Correlation of $\ln \left(\mathrm{H}_{\mathrm{S}}\right)$ and $\ln \left(\mathrm{T}_{\mathrm{P}}\right)$ & 0.65 \\
\hline
\end{tabular}

Table 6. Directional probability of long-term wave distribution

\begin{tabular}{lll}
\hline Wave Direction & Probability & Annual No. \\
\hline Head Sea & 0.50 & 1460 \\
Quartering Sea & 0.30 & 876 \\
Beam Sea & 0.10 & 292 \\
Stern Quartering Sea & 0.05 & 146 \\
Stern Sea & 0.05 & 146 \\
Sum & 1.00 & 2920 \\
\hline
\end{tabular}

Table 7. One hundred year return sea-state in beam sea and quartering sea

\begin{tabular}{|c|c|c|c|c|c|c|c|c|c|c|}
\hline \multirow{2}{*}{$\begin{array}{l}\text { Parameter } \\
T_{P}(s)\end{array}$} & \multicolumn{10}{|c|}{ Values } \\
\hline & 6.0 & 7.0 & 8.0 & 9.0 & 10.0 & 11.0 & 12.0 & 13.0 & 14.0 & 15.0 \\
\hline Hs (m) - Beam Sea & 6.4 & 7.0 & 7.5 & 7.8 & 8.0 & 8.1 & 8.1 & 8.0 & 7.7 & 7.4 \\
\hline Hs (m) - Quartering Sea & 6.9 & 7.6 & 8.1 & 8.5 & 8.8 & 9.0 & 9.0 & 8.9 & 8.8 & 8.5 \\
\hline
\end{tabular}

The commercial software ANSYS ${ }^{\circledR}$ AQWA ${ }^{\mathrm{TM}}$ is used to calculate the hydrodynamic coefficients in frequency domain, using 3D panel method. The AQWA model for FPSO is shown in Figure 3. The x-axis pointing from stern to bow is towards the $0^{\circ}$ direction, and y-axis pointing from starboard to port side is towards $+90^{\circ}$. Thirteen equivalent flexible risers of lazy wave configuration are connected to the portside of the FPSO model around midship, each represent a group of 2 3 neighbour risers and/or umbilicals in real case. Bilge keels are assumed to be $100 \mathrm{~m}$ long on both sides of the vessel. Morrison elements with a constant drag coefficient $\left(C_{D}\right)$ of 8.5 are used to represent the bilge keels. For truncated bilge keel design, the length is reduced by $25 \%$ for bilge keel model at port side and increased by of $25 \%$ for the starboard side. 


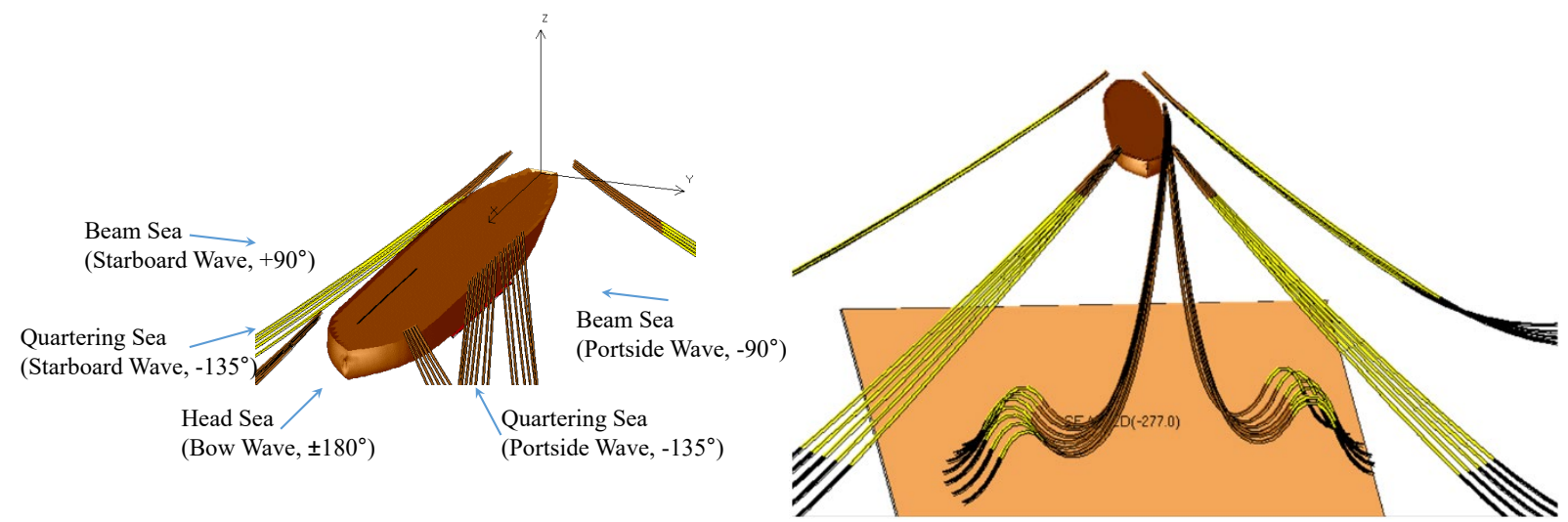

Figure 3. FPSO model in AQWA

\section{Results and discussions}

\subsection{The effect of asymmetric risers}

The effect of asymmetric risers is investigated by comparing the results of model A and B. As there is no asymmetric riser arrangement in model $\mathrm{A}$, the motion response is the same for starboard and portside waves. The ratios between the significant roll motion of model B and model A are plotted in Fig. 4. In the beam sea condition, the roll response of model B to starboard wave is always larger than to portside wave, and slightly larger than that of model A. The roll response of model B to port side wave is lower than model A, with the variation of response ratio strongly related to the severity of sea-state. Generally, the numerical study on model A and B in beam-sea is consistent with the conclusions of Ferreira et al. [4]. The heave-roll coupling effect due to the asymmetric riser arrangements is very significant for most sea-states in the beam-sea condition.

In the quartering sea condition, the roll response of model B to starboard wave is also always larger than to port side wave, but the difference is much smaller which indicates a less critical role of the asymmetric effect. Different from the beam-sea results, in low sea-states like wave \#1 and \#2, the roll response of model B to both starboard wave and portside wave are lower than model A; while in high sea-states like wave \#6 \#10, roll response of model B to both starboard wave and portside wave are higher than model A.

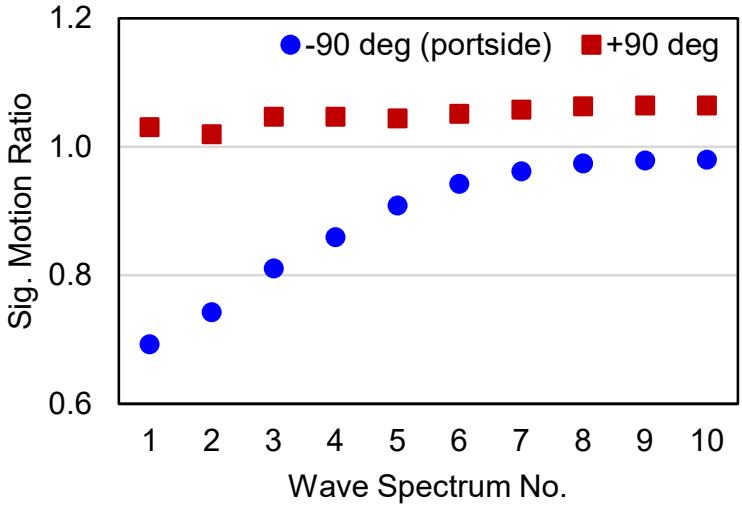

(a) Beam sea condition.

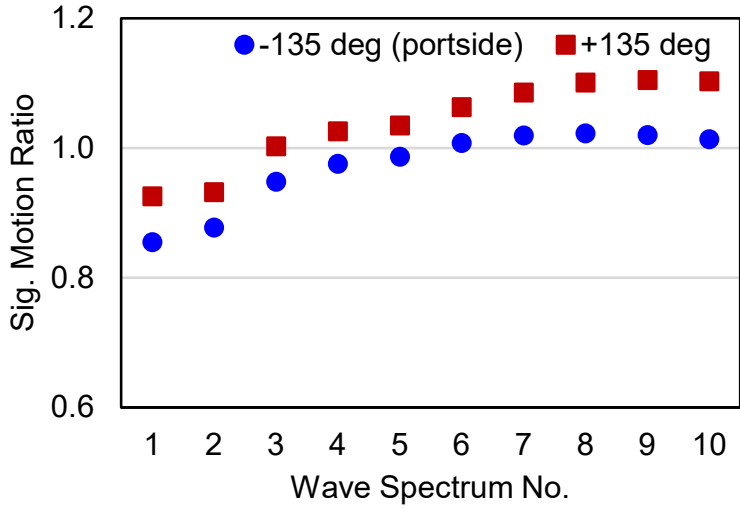

(b) Quartering sea condition.

Figure 4. Significant roll motion ratio (model B / A)

To further understand the roll response comparison shown in Fig. 4, the roll motion RAOs of model A and B are plotted in Figure 5, with quadratic damping being linearized under wave \#10. There are two important observations: (1) the result difference between starboard and portside waves in model B is significant for the wave period of $8 \sim 15 \mathrm{~s}$ (spectrum no. $1 \sim 7$ ) in beam-sea, and $15 \sim 20$ s (spectrum no. $8 \sim 10$ ) in quartering-sea; (2) throughout the whole range of wave periods, the roll response of the model to starboard wave is always larger than that to portside wave. Both these conclusions are consistent with the results presented in Fig. 4. 


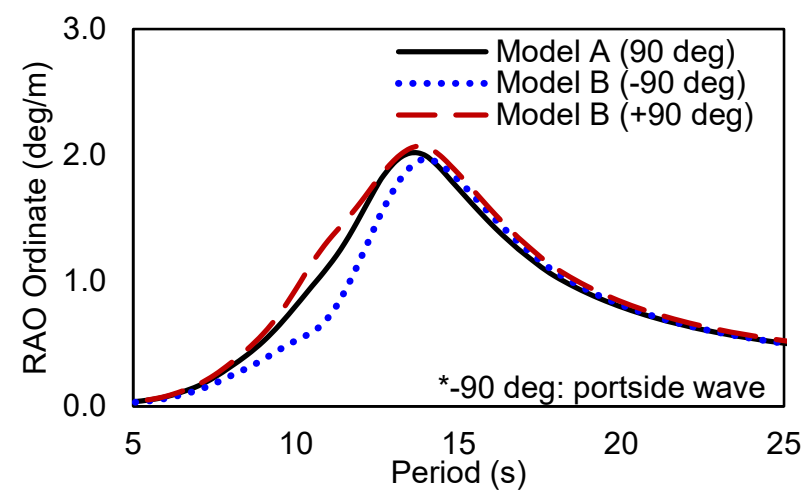

(a) Beam sea condition.

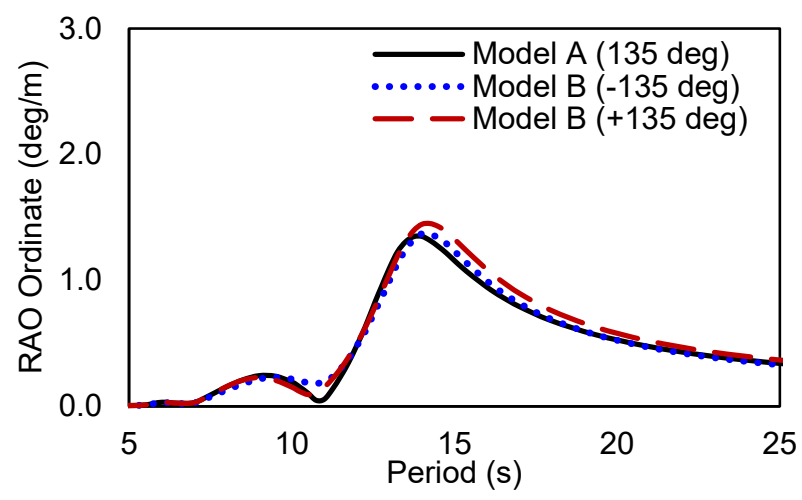

(b) Quartering sea condition.

Figure 5. Roll motion RAOs of model A and B in wave \#10

Figure 6 presents the significant values of the RWE distribution of model B in wave \#1 and \#8 with different wave directions. The results are presented as the ratio of model $\mathrm{B}$ over model $\mathrm{A}$. The comparison shows that the relative wave elevation on FPSO is also affected by the asymmetric risers, but the exact effect is not the same as how the motion response is affected. The asymmetric effect on RWE is less significant compared to the roll motion responses.

In addition, the asymmetric effect may be opposite on the roll motion and the RWE under some wave conditions. For example, the roll motion in the starboard wave is always larger than that in the portside wave in Fig. 4a and 4b. However, as presented in Fig. $6 \mathrm{~b}$ and $6 \mathrm{~d}$, at some locations, the significant RWE in the starboard wave can be smaller than that in the portside wave.

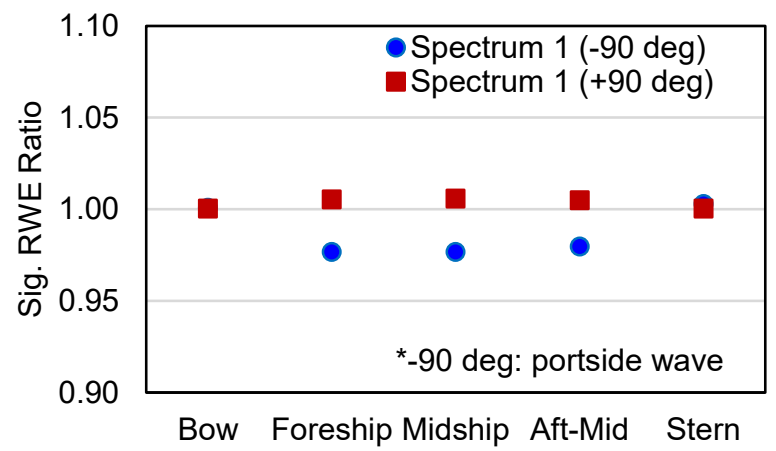

(a) Spectrum \#1 in beam sea

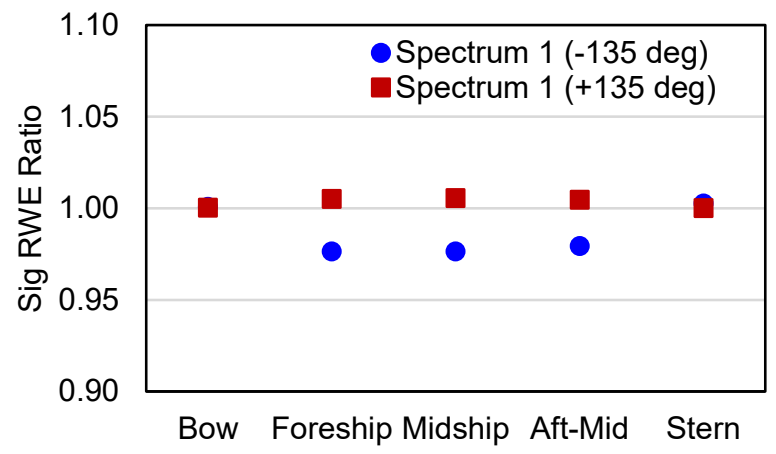

(c) Spectrum \#1 in quartering sea

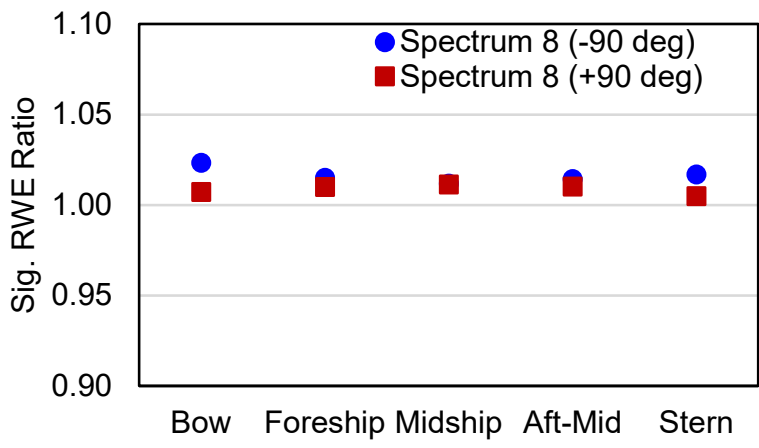

(b) Spectrum \#8 in beam sea

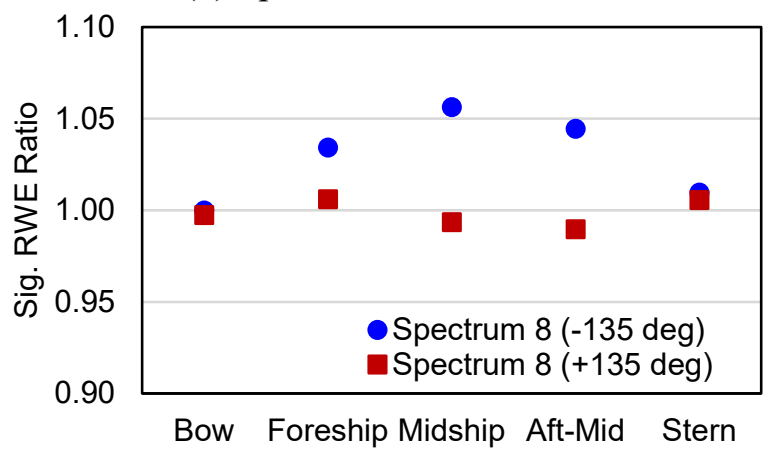

(d) Spectrum \#8 in quartering sea

Figure 6. Significant RWE ratio (model B / A)

The two observations above indicate that the riser effect on RWE appears to be different from that on roll motion, which can be explained by further considering the phase angle of the motions. As illustrated in Eq.(18) , the RWE is consisted of incident wave, diffraction, radiation and vessel motion. Assuming that all the motion 
components are in-phase, the RWE would be the simple summation of the four amplitudes, and larger vessel motion would obviously leads to larger RWE. However, if the motion components are not always in-phase and can be changed, the summation of the four motion components becomes more complicated, and the relation between RWE and vessel motion is not so straightforward. As shown in Fig. 7, beside the motion RAOs, the phases of the motions are also affected by the heave-roll coupling effect due to the asymmetric riser arrangement. Therefore, the non-intuitive observation of riser effects on RWE being different or even opposite to that on roll motion is reasonable.

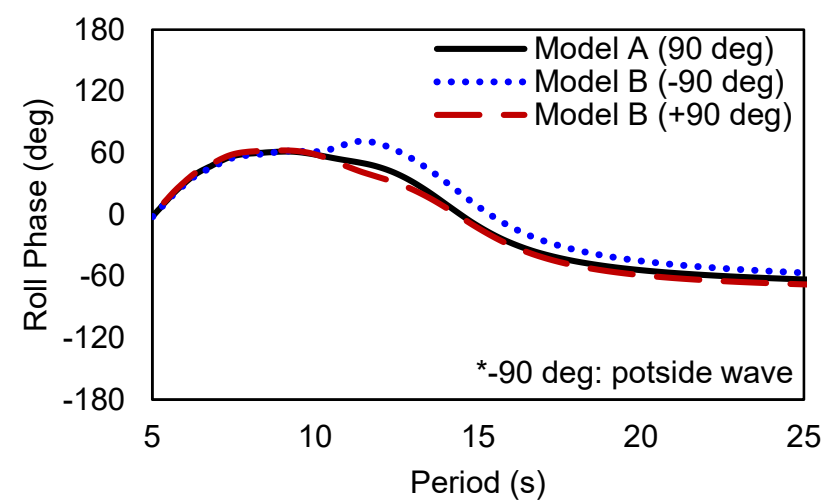

(a) Beam sea condition.

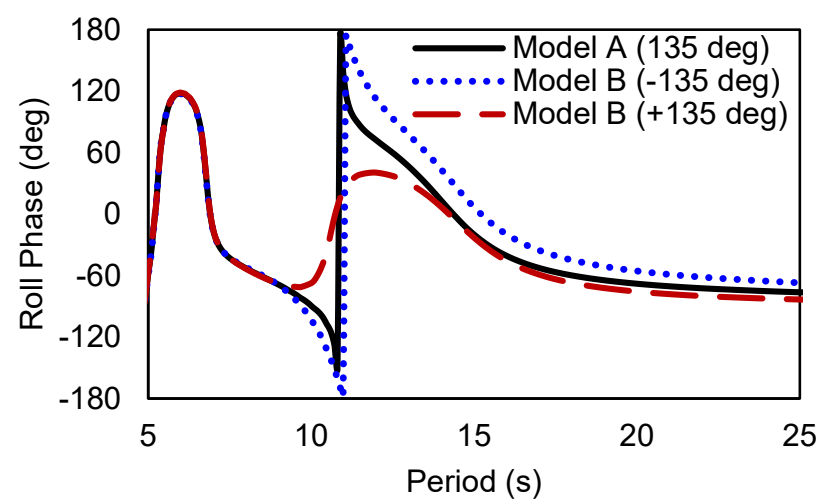

(b) Quartering sea condition.

Figure 7. Roll motion phases of model A and B in wave \#10

The contribution of each component in $\mathbf{H}_{\text {riser }}$ has also been investigated. Table 8 compares the roll added mass, damping and stiffness coefficients of the riser lines with the total values of the system, taking from model B in portside beam sea (wave spectrum \#8). It can be seen that the added mass of the riser lines has the largest contribution, while the effects of damping and stiffness of the riser lines are smaller. This conclusion contradicts the finding by Rezende et al. [9], who concluded that the damping effect of the riser was the most significant and the inertia term might be negligible. The FPSO model used in this study operates in a shallow water environment while the model studied by Rezende et al. [9] operates in the deep sea environment. As the damping effect of risers has a nature of quadratic drag, and also closely related to the dynamic line behavior, the increase in water depth and riser length may rapidly increase the damping level, thus making the effect of added mass relatively small. We believe this might be the reason why the conclusions on contributions of the riser inertia and damping can be different in the two studies.

Table 8. Comparison of added mass, damping, and stiffness in $H_{\text {riser }}^{44}$

\begin{tabular}{lll}
\hline$A_{\text {riser }}^{44} /\left(I_{44}+A_{\text {total }}^{44}\right)$ & $B_{\text {riser }}^{44} / B_{\text {total }}^{44}$ & $K_{\text {riser }}^{44} / K_{\text {total }}^{44}$ \\
\hline $4.99 \%$ & $3.31 \%$ & $0.07 \%$ \\
\hline
\end{tabular}

We have also compared the importance of the diagonal and non-diagonal terms in $\mathbf{H}_{\text {riser }}$. Figure 8 shows the roll amplitude and phase for four models: 1 . No riser; 2. Include all terms of the riser matrix; 3 . Include only the diagonal inertia terms of the riser matrix; 4. Include only the non-diagonal inertia terms of the riser matrix. The results of the model that only considers the non-diagonal terms show a very close approximation to the results considering all riser terms. Therefore, it is evident that for this case the non-diagonal inertia terms in the riser matrix have a more significant influence on the motion response of the vessel than the diagonal terms, and only the diagonal terms can be estimated directly from decay test. Besides, the effect of the asymmetric riser in Fig. 8 is showing a significant dependency on the period: it is significant for periods of $9 \sim 14 \mathrm{~s}$, but almost negligible for other periods. Therefore, to capture a comprehensive overview of the asymmetric riser effect in 
general circumstances, numerical study should be performed in various periods, and the heave-roll coupling effect or the equivalent non-diagonal hydrodynamic coefficients contributed by the asymmetric risers must be included in the study.

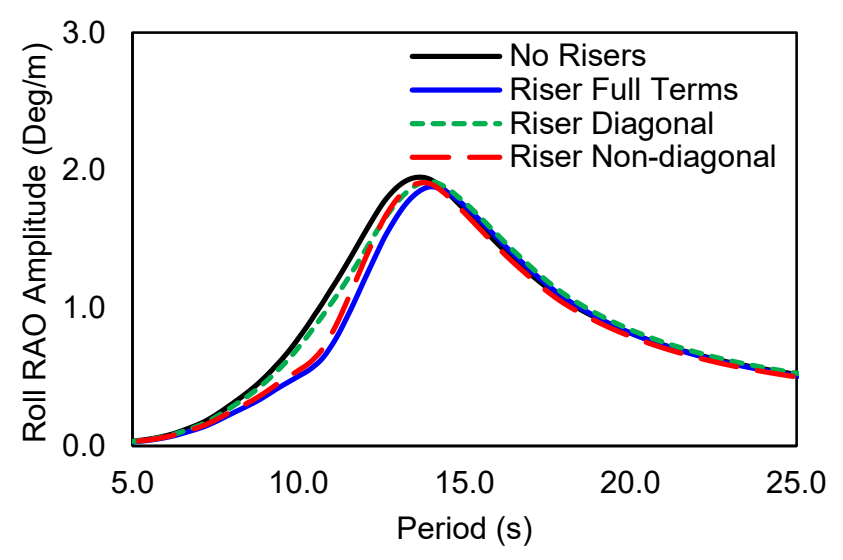

(a) Roll amplitude

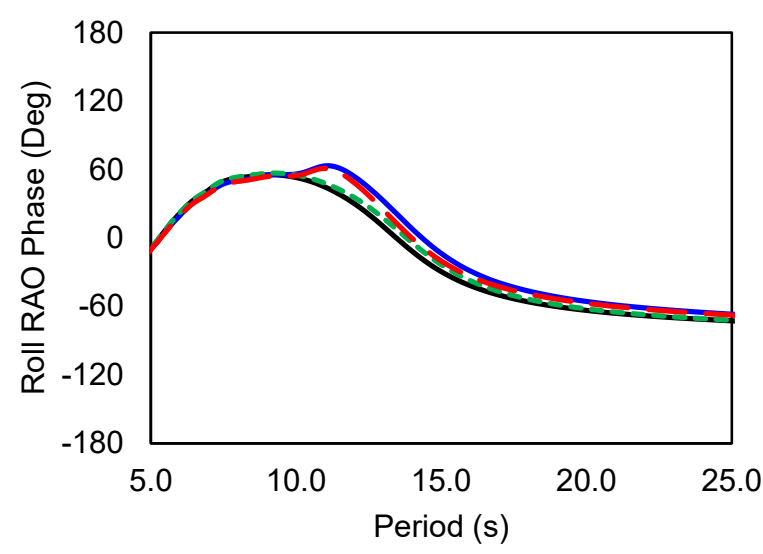

(b) Roll phase

Figure 8. Comparison of roll amplitude and phase with different terms of the riser matrix

The long-term extreme RWE responses are obtained using both the traditional approach and response-based analysis. The RWEs on different locations of the FPSO for a 100-year return period are shown in Figure. 9. Similar as above, the results are presented as the ratio of model B over model A. For long-term extreme responses, the asymmetric effect can be observed in the beam-sea condition, and it becomes almost negligible in the quartering-sea condition, despite the clear asymmetric short-term roll response shown in Fig. 4b. In the beam-sea condition, the RWE response to starboard wave is slightly higher than the portside wave. It can also be seen that the contour line approach and response-based analysis gives a very close prediction.

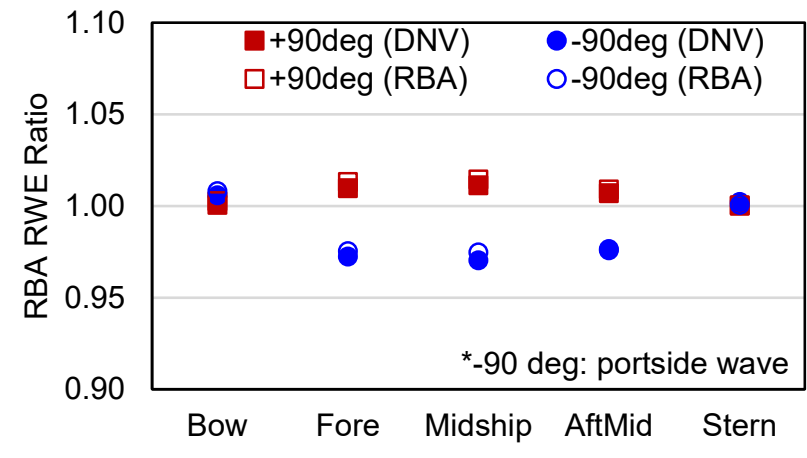

(a) Beam sea condition.

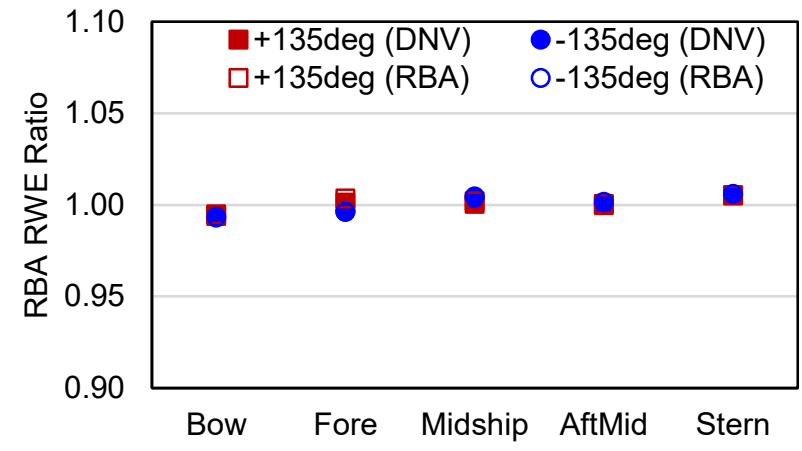

(b) Quartering sea condition.

Figure 9. 100-year return RWE-MPM ratio (model B / A)

\subsection{The effect of truncated bilge keel with asymmetric risers}

For an FPSO with both truncated bilge keel and asymmetric risers, the two asymmetric effects can be at opposite side, acting against each other. Studies by Tom et al. [6], Seah et al. [7] and Bigot et al. [8] suggested that the effect of asymmetric bilge keel is mainly due to quadratic damping. Rezende et al. [9] claimed that the inertia effect of asymmetric risers is insignificant in their study, and simplified the riser effect using Morrison element. In such case, it is possible that the asymmetric effect of bilge keel and risers at opposite side will cancel with each other, leading to a reduced overall asymmetric effect dominated by the stronger side; in the condition of perfect cancellation, the FPSO may even have a symmetric response to waves from both sides. On the other hand, the discussions in the previous section of this article shows that the effect of asymmetric risers in our case study is mainly contributed by inertia. In such case, due to the different nature of the quadratic damping and 
inertia, the cancellation between two asymmetric effects is expected to be depending on the environmental seastate, and the overall behavior of the FPSO shall become more complicated.

The significant roll motion ratio of (model C / model A \& B) are plotted in Fig. 10. Figure 10a shows the effect of the truncated bilge keel, with apparent dependence on the severity of sea-state: in low sea-states \#1 \#3, the asymmetric effect of truncated bilge keel is not significant; however, in higher sea-states, the effect gradually becomes non-negligible. Fig. 10b shows the combined effect of asymmetric risers and truncated bilge keel. In low sea-states (\#1 \#4), the roll response ratio of model C/model A to wave from portside are lower than 1 , and similar trend for model B/model A is presented in Fig. 4a; in high sea-states (\#7 \#10), the asymmetric effect is dominated by the damping of truncated bilge keel, and the trend becomes opposite: the roll response ratio of model C/model A to portside wave in Fig. $10 \mathrm{~b}$ are higher than 1, while the ratio of model B/model A to portside wave in Fig. 4 a are lower than 1.

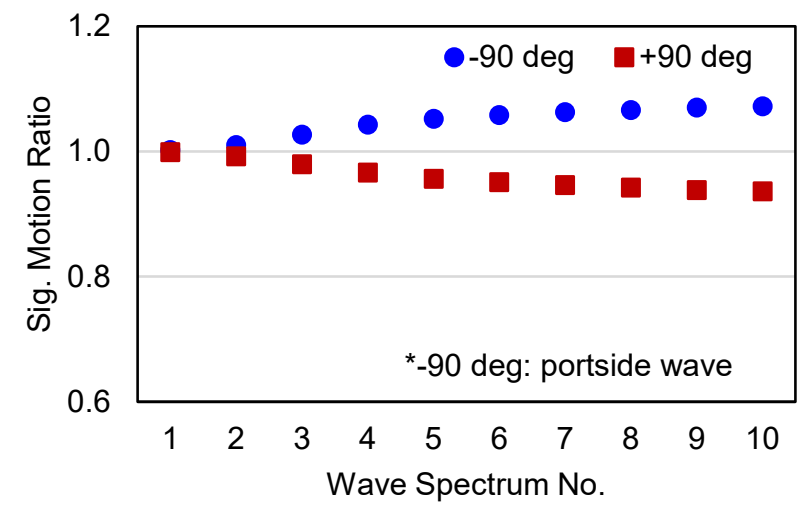

(a) Ratio of model C / model B

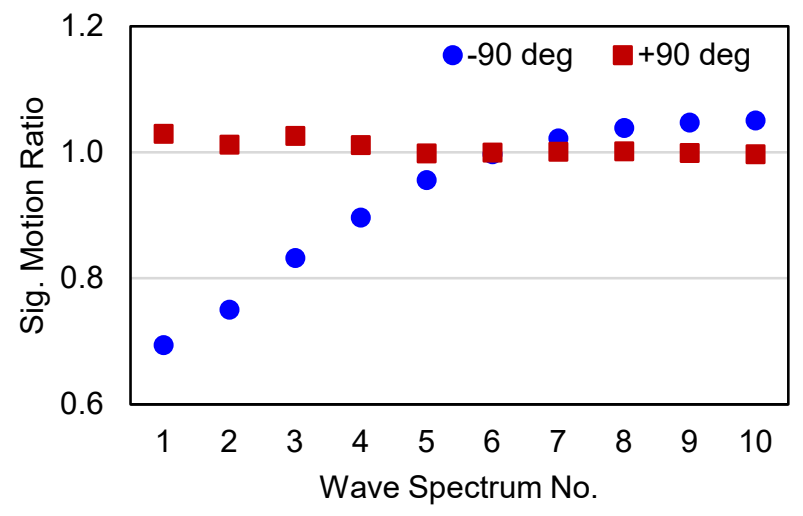

(b) Ratio of model C / model A

Figure 10: Significant roll motion ratio (model C / model A \& B)

The significant values of RWE from model $\mathrm{C}$ in wave \#1, \#6 and \#8 are calculated and presented in Fig. 11 as the ratio between model $\mathrm{C}$ and model $\mathrm{A}$. The combined effects of the asymmetric riser and truncated bilge keel on the relative wave elevation observed in Fig. 11 is very similar to that on roll motion responses (Fig. 10b), in which the response induced by the wave from +90 degrees is higher than from -90 degrees in mild sea-state (spectrum \#1), and lower than from -90 degrees in high sea-state (spectrum \#8). However, for spectrum \#6, while the FPSO has the same roll motion response to sea-state from both sides, the RWE response is still asymmetric. This is because the asymmetric effect of truncated bilge keel has a nature of quadratic damping so that it can never have "perfect cancellation" with inertia effect of the asymmetric riser at the opposite side. The "symmetry" observed on roll motion response of the vessel should not be considered as valid for RWE, nor any other response (i.e. equipment acceleration, mooring line tension, riser stress, etc.), in the same sea-state.

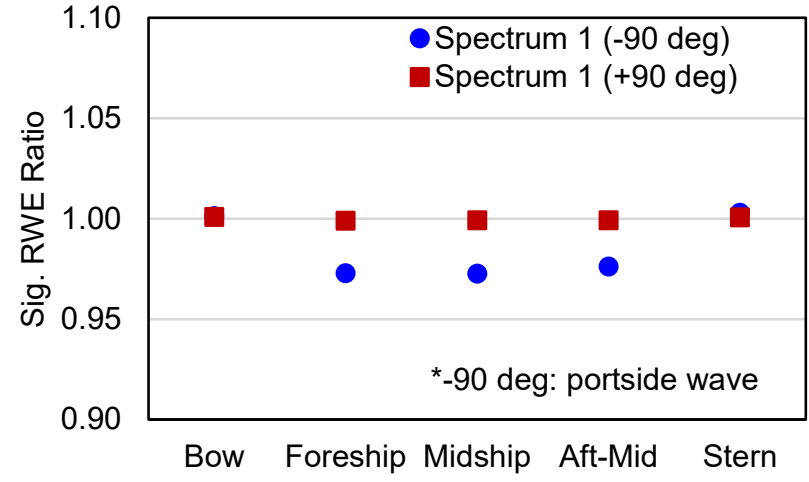

(a) Wave spectrum \#1

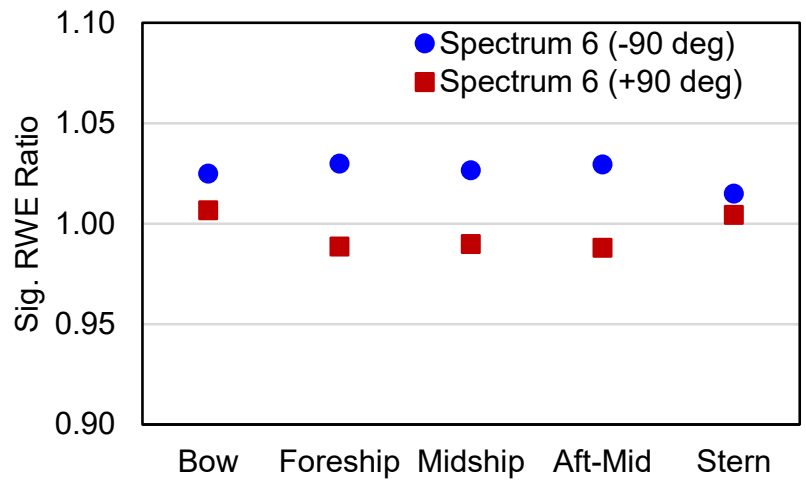

(b) Wave spectrum \#6 


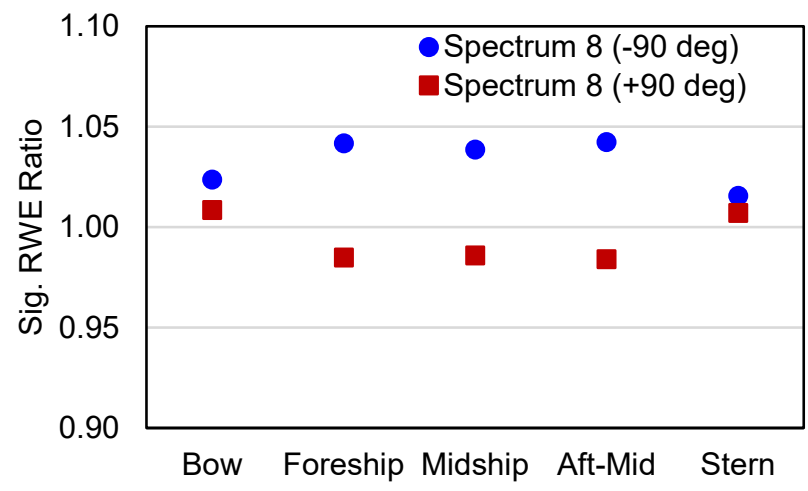

(c) Wave spectrum \#8

Figure 11: Significant RWE ratio (model C / model A)

The long-term RWE result of model C for the 100-year return period is shown in Fig. 12, using both traditional approach and response-based analysis. The results are presented as the ratio of RWE from model C divided by RWE from model A. For the long-term extreme response to the wave from portside, the overall asymmetric effect can be clearly observed, in which the waves from starboard side (+90deg) induced higher RWE than from portside (-90deg). Besides, RBA results also indicate that the 100-yr return RWE on model C is almost the same as on model A in portside waves, and higher than on model A in starboard side waves. However, results from traditional approach show that the 100-yr return RWE on model C is lower than on model A in portside waves and similar to model $\mathrm{A}$ in starboard side waves. The traditional approach wrongly suggests that the RWE response on the asymmetric model $\mathrm{C}$ in beam sea is, in general, less severe than on the symmetric model $\mathrm{A}$, which is opposite to the RBA results. In Fig. 12, a difference of $2 \% \sim 3 \%$ on the RWE results between traditional approach and RBA can be identified from the comparison. This discrepancy demonstrates the limitation of the traditional approach in evaluating the combined asymmetric effect of bilge keel and risers to the long-term RWE response of an FPSO.

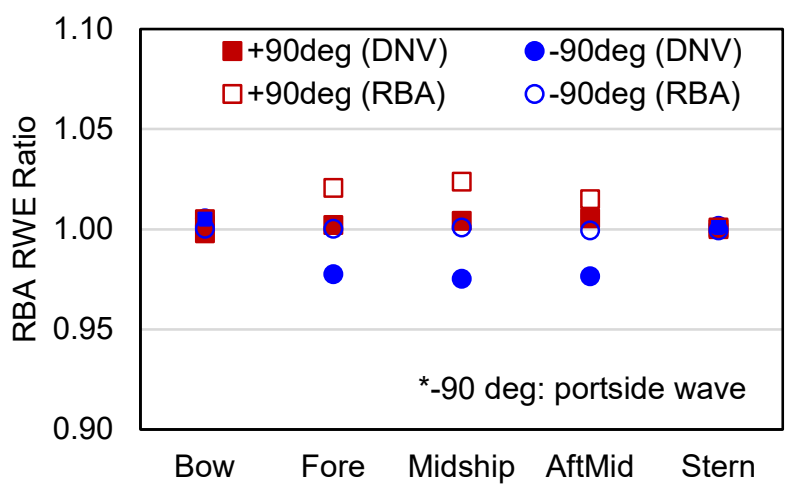

Figure 12. 100-year return RWE-MPM ratio (model C / A)

By further utilizing the data generated during RBA calculation, the response of roll motion and midship RWE on model C in beam sea waves from portside (-90deg) and starboard side (+90deg) are compared in Fig. 13, to obtain an overview of the combined asymmetric effect of bilge keel and risers with respect to $\mathrm{H}_{\mathrm{S}}$ and $\mathrm{T}_{\mathrm{P}}$ of seastates. The ratio of significant roll motion is presented in Fig. 13(a), and ratio of significant RWE at midship is presented in Fig. 13(b). The ratio above 1 means response in starboard side wave is higher than in portside wave. 
(a) Significant $\mathrm{X}_{4}$ Ratio
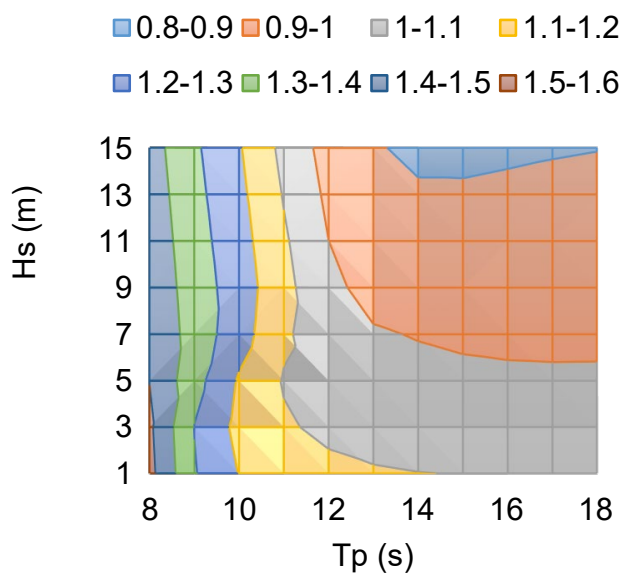

(b) Significant RWE Ratio

$\square 0.94-0.96 \square 0.96-0.98 \square 0.98-1$

$\square 1-1.02 \quad \square 1.02-1.04 \square 1.04-1.06$

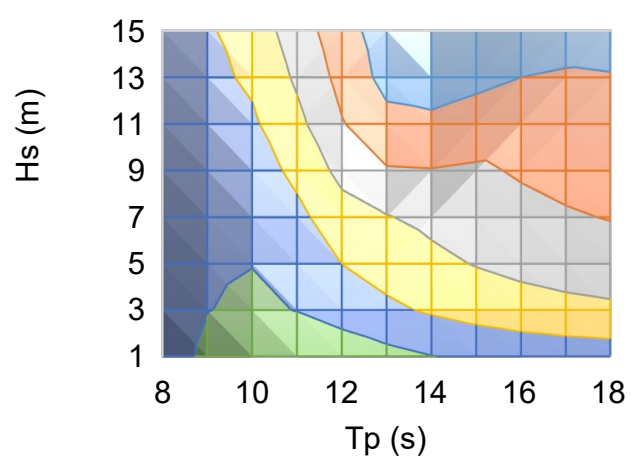

Figure 13. Response Ratio from Model C (+90deg/-90deg)

As shown in the figure, when $\mathrm{H}_{\mathrm{S}}$ and $\mathrm{T}_{\mathrm{P}}$ are high, as the damping effect from truncated bilge keel overcomes the inertia effect from portside risers, the responses on model $\mathrm{C}$ in starboard waves are generally lower than those in portside waves; when $\mathrm{H}_{\mathrm{S}}$ and $\mathrm{T}_{\mathrm{P}}$ are low, the damping effect from truncated bilge keel is low and the inertia effect from portside risers dominates the asymmetric effect, and the responses on model $\mathrm{C}$ in starboard waves are generally higher than those in portside waves. However, the detailed trend of the response ratio in the figures appear to be complicated. In addition, it also can be observed that for sea-states with $T_{P}$ of $8 \mathrm{~s} \sim 12 \mathrm{~s}$, the ratio of roll motion is dominated by $\mathrm{T}_{\mathrm{P}}$, while the ratio of RWE appears to be also largely affected by $\mathrm{H}_{\mathrm{S}}$.

\section{Conclusions}

Numerical case studies are carried out on a real FPSO project to investigate the effects of asymmetric riser and bilge keel arrangements on the motion response and relative wave elevation. A practical and efficient method for short-term and long-term prediction is proposed and applied. From the numerical analysis presented in this paper, the following conclusions are obtained:

- The asymmetric effect of risers on the roll motion and RWE response of the target FPSO in beam-sea and oblique waves are dominated by the non-diagonal inertia terms of risers, which affects both the amplitude and phase of roll motion RAO, by introducing a coupling between the roll and heave degree-of-freedom.

- The asymmetric effect of bilge keel contributed by Morrison type drag force has a nature of quadratic damping, thus will not have perfect cancellation with inertia effect of the asymmetric riser at the opposite side. The combination of asymmetric riser effect and truncated bilge keel effect makes the overall asymmetric effect more complicated, and mainly depending on environmental conditions.

- From the short-term response, it can be observed that both the roll motion and significant RWE are affected by the asymmetric effect; however, the detailed trends of roll motion and RWE can be different, due to the phase difference between incident wave and vessel motion.

- The long-term RWE response is also affected by the asymmetric arrangement of risers and bilge keel. Traditional approach and RBA agrees well in predicting the RWE ratio caused by asymmetric effect only from risers, with the main contribution from non-diagonal inertia terms. However, for the combined asymmetric effect from both risers and truncated bilge keel to long-term RWE, discrepancy between results from traditional approach and RBA is evident in this study.

In future work, it would be very valuable to carry out systematic comparisons between RBA and traditional approaches, using various types of long-term sea state distribution models, scatter diagrams from different sites (i.e. North Sea, Gulf of Mexico, South China Sea, Australia, Brazil, West Africa, etc.), as well as comparing to 
traditional approach using various alternative methods on metocean analysis (iFORM, HDC, etc.), so that a more generalized estimation on the differences between traditional approach and RBA may be provided as reference for industrial application.

\section{Acknowledgments}

The authors are grateful for the financial support by Singapore Economic Development Board Industrial Postgraduate Programme and Sembcorp Marine Ltd, which enabled them to carry out the research in this paper.

\section{Appendix - Stochastic linearization of the quadratic damping coefficient}

The drag force due to the quadratic damping is usually given as

$$
D=B^{q}|V| V
$$

Here, $V$ can be the local velocity at the riser connection or bilge keel, or the global motion velocity $\dot{X}_{i}(i=1 \sim 6)$. Assuming $V$ in irregular waves is a Gaussian random process, the stochastic linearization can be applied. The equivalent linear damping coefficient is given as

$$
\tilde{B}^{q}=B^{q} \sqrt{\frac{8}{\pi}} R M S(V)
$$

where $R M S(V)$ denotes the root mean square of $V$.

An iterative approach is taken to obtain the linearized quadratic damping coefficient. First, an initial guess of $R M S(V)=R M S\left(V_{i}\right)$ is made (for example, zero) to get $\tilde{B}^{q}$, and the motion response RAO is then obtained. The motion response spectrum then can be calculated using the motion RAO and the selected wave spectrum. The spectrum of $V$ distribution can then be obtained, which can be used to calculate $R M S(V)=R M S\left(V_{i+1}\right)$. The obtained $\operatorname{RMS}\left(V_{i+1}\right)$ will then be used as the new guess to calculate the new value of $\tilde{B}^{q}$ in the next iteration. The iteration is stopped when the normalized difference between $R M S\left(V_{i}\right)$ and $R M S\left(V_{i+1}\right)$ are smaller than the converging criteria $\left(1 \times 10^{-9}\right.$ in this research). Figure A1 summarizes the process of this iteration.

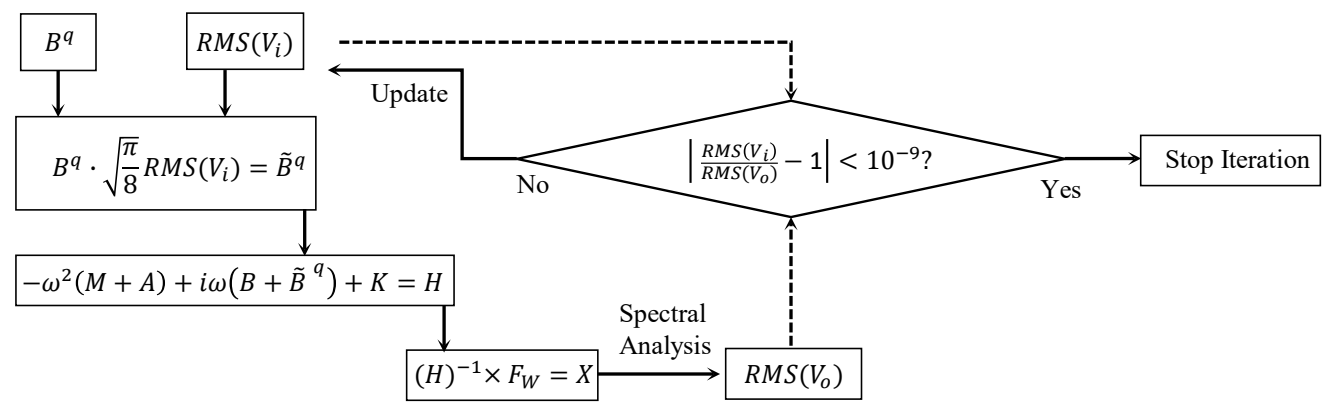

Figure A1. Iterative process for stochastic linearization on quadratic damping coefficient

\section{References}

[1] Buchner, B. (1995). The impact of green water on FPSO design. 27th Offshore Technology Conference, OTC1995, Houston, TX, USA.

[2] Greco, M., Lugni, C., Colicchio, G. and Faltinsen, O.M. (2015). Numerical study of bilge-keel effect on parametric roll and water on deck for an FPSO. Proceedings of 34th International Conference on Ocean, Offshore and Arctic Engineering, St. John's, Newfoundland, Canada.

[3] England, L.T., Duggal, A.S., and Queen, L.A. (2001). A comparison between turret and spread moored F(P)SOs for deep water field development. Deep Offshore Technology Symposium 2001.

[4] Ferreira, M.D., Oliveira, M.C., Carvalho, R.C. and Sphaier S.H. (2012). Asymmetric FPSO roll response due to the influence of lines arrangement. Proceedings of 31st International Conference on Ocean, Offshore and Arctic Engineering, Rio de Janeiro, Brazil. 
[5] Veer, R.V., Fathi, F., Khrian, J.G. (2011). On roll hydrodynamics of FPSO's fitted with bilge keels and riser balcony. In: Proceedings of the 30th International Conference on Ocean, Offshore and Arctic Engineering (OMAE), Rotterdam, Netherlands.

[6] Tom, N., Seah, R. and Roddier, D. (2012). Analysis of roll motion due to asymmetric bilge keels. Proceedings of 31st International Conference on Ocean, Offshore and Arctic Engineering, Rio de Janeiro, Brazil.

[7] Seah, R., Bigot, F., Tom, N. and Roddier, D. (2014). A comparison of time domain methods for asymmetric roll predictions. Proceedings of 33rd International Conference on Ocean, Offshore and Arctic Engineering, San Francisco, CA, USA.

[8] Bigot, F., Seah, R., Derbanne, Q. and Hauteclocque, G. (2014). Prediction of asymmetric FPSO roll using a frequency domain method. Proceedings of 33rd International Conference on Ocean, Offshore and Arctic Engineering, San Francisco, CA, USA.

[9] Rezende, F., Vivas, L., and Carre, A. (2017). Effect of coupling of mooring and riser systems and FPSO roll motions on the design of flexible risers. In: 49th Offshore Technology Conference, Houston, Texas.

[10] Wang, S., Wang, X. and Woo, W.L. (2017). Numerical green water assessment for an FPSO with consideration of nonlinear effects from bilge keel, spread mooring and asymmetric risers. Proceedings of 27th International Offshore and Polar Engineering Conference, San Francisco, CA, USA.

[11] Wang, S., Wang, X., Woo, W.L. and Seow, T.H. (2017). Study on green water prediction for FPSOs by a practical numerical approach. Ocean Engineering, 143, 88-96.

[12] Wang, S., Wang, X. and Woo, W.L. (2018). A comparison of response-based analysis and environmental contour methods for FPSO green water assessment. Proceedings of the 37th International Conference on Ocean, Offshore and Arctic Engineering (OMAE), Madrid, Spain.

[13] Wang, S., Wang, X. and Woo, W.L. (2018). On the application of simplified CFD model in assisting FPSO green water assessment at bow. Proceedings of 28th International Offshore and Polar Engineering Conference, Sapporo, Japan.

[14] Ochi, M.K. (1964). Extreme behaviour of a ship in rough seas slamming and shipping of green water. Annual Meeting SNAME.

[15] Burrows, R., and Salih, B.A. (1986). Statistical modelling of long-term wave climates. Coastal Engineering.

[16] Teng and Palao Teng, C.C., and Palao, I.M. (1996). Wave height and period distributions from long-term wave measurement. Coastal Engineering.

[17] Ochi, M.K. (1978). Wave statistics for the design of ships and ocean structures. Annual Meeting SNAME.

[18] Haselsteiner, A.F., Ohlendorf, J.-H., Wosniok, W., and Thoben, K.-D. (2017). Deriving environmental contour from highest density region. Coastal Engineering, 123, 42-51.

[19] Det Norske Veritas. (2010). Recommended Practice - DNV-RP-C205 Environmental Conditions and Environmental Loads.

[20] API-RP-2SK. (2005). Recommended Practice for Design and Analysis of Stationkeeping System for Floating Structures. Third edition, American Petroleum Institute, October 2005. 